\title{
The association between primary open-angle glaucoma and fall: an observational study
}

This article was published in the following Dove Press journal:

Clinical Ophthalmology

I March 2012

Number of times this article has been viewed

\author{
Sachiko Tanabe ${ }^{1,2 *}$ \\ Kenya Yuki ${ }^{1 *}$ \\ Naoki Ozeki' \\ Daisuke Shiba' \\ Kazuo Tsubota' \\ 'Department of Ophthalmology, \\ Keio University School of Medicine, \\ Shinanomachi 35, Tokyo, Japan; \\ ${ }^{2}$ Tanabe Eye Clinic, Kai City, \\ Yamanashi, Japan \\ *These authors contributed equally \\ to this work
}

Correspondence: Kenya Yuki Department of Ophthalmology, Keio University School of Medicine, 35 Shinanomachi, Shinjuku-ku, Tokyo, 160-8582, Japan

Tel +8I 33353 I 2II, ext 63919

Fax +81333598302

Email yukikenya@a6.keio.jp
Purpose: Falls are among the most serious public health concerns for the elderly. Information conveyed via the visual sense is relevant to postural balance and movement, and proper visual function is essential to avoid falls. Here we investigated the prevalence of injurious falls among patients with primary open-angle glaucoma (POAG) who were more than 45 years old, compared with comparably aged healthy subjects.

Methods: This is a cross-sectional study. Consecutive patients who visited the Tanabe Eye Clinic, Yamanashi, Japan between January 1 and March 30, 2009 were screened for eligibility by ophthalmic examination. A total of 117 control subjects (77 men, 40 women; aged $60.2 \pm 7.5$ years) who were free of ocular disease and 101 POAG patients (58 men, 43 women; aged $62.3 \pm 8.7$ years) were consecutively enrolled. Participants answered a questionnaire on injurious fall experience during the previous 10 years. The prevalence of injurious fall in subjects with POAG versus healthy controls was examined with Fisher's exact test. Adjusted odds ratios and $95 \%$ confidence intervals were estimated with logistic regression models for the subjects with POAG (factors: age, gender, mean deviation in the better eye or worse eye).

Results: The self-reported prevalence of injurious fall was $0.9 \%(1 / 117)$ in the control group and $6.9 \%(7 / 101)$ in the POAG group. The association between injurious fall and POAG was statistically significant $(P=0.026$, Fisher's exact test). Within the POAG patients, the group reporting falls was significantly older and had a lower BMI, worse BCVA, and worse mean deviation in both the better and worse eye than the group reporting no falls. Worse mean deviation in the eye with the better visual field (odds ratios $0.75 ; 95 \%$ confidence intervals: 0.57 to 0.99 ; $P=0.036$ ) was a significant risk factor for injurious falls in subjects with POAG.

Conclusions: POAG was significantly associated with injurious falls.

Keywords: primary open-angle glaucoma, fall, visual field defect, injury

\section{Introduction}

Falls are among the most serious public health concerns for the elderly, worldwide. About $30 \%$ of individuals over the age of 75 years fall at least once in a year; $10 \%-20 \%$ of the falls lead to injury, and 5\%-6\% result in fractures. ${ }^{1,2}$ Falls are associated with restricted activity, ${ }^{3}$ hospitalization, ${ }^{4}$ subsequent admission to a nursing home, ${ }^{5}$ and injury-related death. ${ }^{6-8}$

Glaucoma is the second leading cause of blindness in the world, affecting approximately 5 million adults globally; it is the leading cause of blindness in Japan. ${ }^{9,10}$ A previous study reported that glaucoma is not diagnosed in $93.3 \%$ of Japanese people with the disease, even though they have significant visual field defects. ${ }^{10}$ Furthermore, many of those with diagnosed glaucoma have little awareness of the disease, probably 
because the visual field loss in many cases occurs only in the peripheral areas, and visual acuity is preserved for a relatively long period. This implies that many patients with glaucoma do not realize that they have visual field defects.

Several factors, such as age, gender, postural hypotension, the use of multiple medications, impairment of cognition, balance, gait, ${ }^{2}$ or vision, ${ }^{11-15}$ increase the risk of falling and fall-related injuries. Information conveyed via the visual sense is relevant to postural balance ${ }^{16}$ and movement, ${ }^{17}$ and proper visual function is essential for avoiding a fall.

In a large-scale prospective cohort study, Coleman et al reported that $13 \%$ of the subjects with no bilateral visual field loss reported falling, compared with $16 \%, 19 \%$, and $22 \%$ of subjects with mild, moderate, and severe bilateral visual field loss, respectively, and this trend was statistically significant. ${ }^{14}$ In the Salisbury Eye Evaluation Project, subjects with bilateral, not unilateral, glaucoma had more trouble performing balance tasks and bumped into objects more frequently. ${ }^{18}$ However, the association between injurious fall and primary open-angle glaucoma (POAG) has not been fully investigated.
The objective of this study was to investigate the prevalence of injurious falls among patients with POAG who were more than 45 years old, in comparison with comparably aged healthy subjects.

\section{Patients and methods}

The procedures used in this study conformed to the tenets of the Declaration of Helsinki and to national (Japanese) and institutional (Keio University School of Medicine) regulations. This study was approved by the Ethics Committee of the Keio University School of Medicine.

\section{Study design and subject enrollment}

The design of this cross-sectional study and subject enrollment procedures are summarized in Figure 1. Those who visited the Tanabe Eye Clinic, Yamanashi, Japan between January 1 and March 30, 2009 were screened for eligibility by means of an ophthalmic examination that included slit-lamp biomicroscopy, funduscopy, gonioscopy, intraocular pressure measurements with Goldmann applanation tonometry, and visual field examination with a static visual field analyzer,

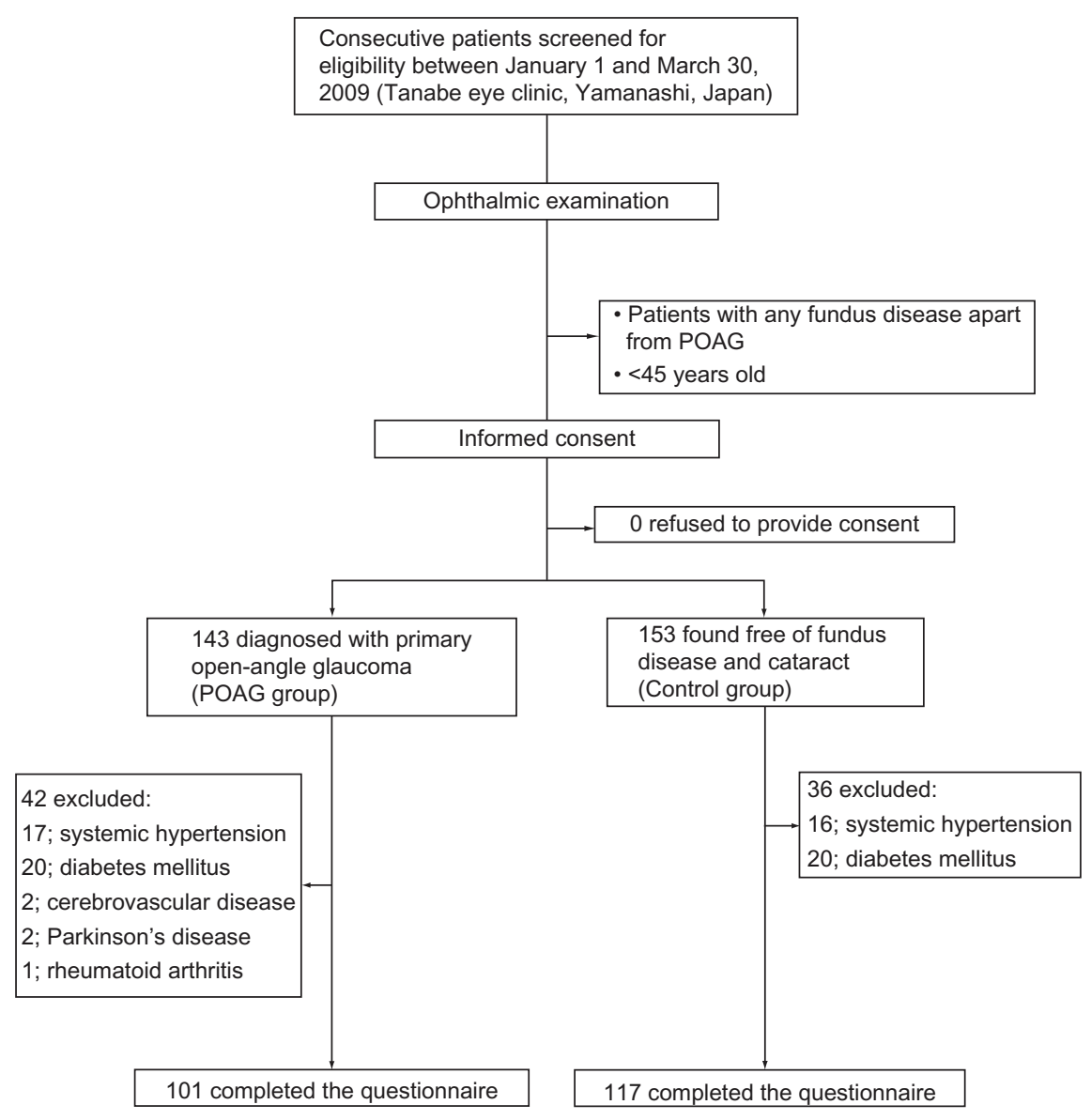

Figure I Design of the cross-sectional study and subject enrollment procedures. 
using the 30-2 Swedish Interactive Threshold Algorithm Standard Strategy (Carl Zeiss Meditec, Dublin, CA) in the glaucoma subjects. Patients with ophthalmologic diseases that could potentially compromise visual acuity or visual field loss, such as age-related macular degeneration, and fundus disease apart from POAG, were excluded. Patients younger than 45 were also excluded. The study methods were explained to every patient who met the inclusion criteria, and all of them agreed to participate.

Written informed consent was obtained from all of those enrolled. A single ophthalmologist (ST) subspecializing in glaucoma performed all of the examinations.

\section{POAG diagnostic criteria}

POAG was diagnosed in 143 patients according to the following three findings: (1) glaucomatous optic cupping represented by notch formation, generalized enlargement of cupping, senile sclerotic disc or myopic disc, or nerve fiberlayer defects; (2) typical glaucomatous visual field defects such as Bjerrum scotoma, nasal step, or paracentral scotoma compatible with optic disc appearance; and (3) open angle observed on gonioscopy.

\section{Control subject inclusion criteria}

The 153 control participants were mostly outpatients who visited the clinic for such purposes as annual ophthalmologic check-ups, screening and correction of refractive errors, or treatment of external ophthalmopathy. All control participants were free of fundus disease and cataracts affecting visual acuity.

\section{Exclusion criteria}

Patients were excluded from the study if they had any systemic disease, including but not limited to diabetes mellitus, systemic hypertension, cerebrovascular disease, Parkinson's disease, and rheumatoid arthritis. Those who could not understand the questionnaire were also excluded. These criteria resulted in the exclusion of 42 subjects (hypertension, 17 subjects; diabetes mellitus, 20; cerebrovascular disease, 2; Parkinson's disease, 2 ; rheumatoid arthritis, 1) from the POAG group and 36 subjects (hypertension 16; diabetes mellitus, 20) from the control group.

\section{Questionnaire}

All participants were requested to fill out a questionnaire on their demographic characteristics, ie, age, sex, weight, height, history of smoking, and consumption of alcohol, and were asked if they had been injured in a fall during the past ten years (yes or no). The answers to the questionnaire were collected and analyzed in a masked fashion to avoid observer bias.

\section{Statistical analysis}

Descriptive statistics were calculated for the demographic, medical, and visual function variables. The homogeneity of distributions between the POAG and control groups was examined with an unpaired $t$-test or Fisher's exact test, depending on the variable. Differences between the group of POAG subjects who reported falling and those who reported no falls were also examined. The adjusted odds ratios (OR) on injurious fall and 95\% confidence intervals (CIs) were estimated with logistic regression models (factors: age, gender, (1) mean deviation (MD) in the better visual field eye or (2) MD in the worse visual field eye).

\section{Results}

A total of 117 control subjects ( 77 men, 40 women; aged $60.2 \pm 7.5$ years) and 101 POAG patients (58 men, 43 women; aged $62.3 \pm 8.7$ years) were recruited. All the participants were ethnic Japanese. The demographic characteristics of the controls and POAG subjects are summarized in Table 1.

The self-reported prevalence of injurious fall was $0.9 \%$ $(1 / 117)$ in the control group and 6.9\% (7/101) in the POAG group. The association between the occurrence of injury by fall and POAG was statistically significant $(P=0.026$, Fisher's exact test, Table 2).

Within the POAG subjects, the group reporting falls was significantly older and had a lower BMI, worse BCVA, and worse MD in both the better and worse eye, compared to the group reporting no falls (Table 3 ). Worse MD in the better visual field eye (OR 0.75; 95\% CI, 0.57 to $0.99 ; P=0.04$, adjusted for age and gender) was a significant risk factor for injurious fall in subjects with POAG, but not better MD in the worse visual field eye (OR $0.83 ; 95 \%$ CI, 0.68 to 1.02 ; $P=0.07$, adjusted for age and gender).

\section{Discussion}

The current study demonstrated that POAG is associated with an increased frequency of injurious falls. These results were compatible with previous reports. ${ }^{19-22}$

In our study, a total of 218 participants experienced 8 injurious falls over the recall period of 10 years $(3.9 \%$ for 10 years; average annual rate, $0.4 \%$ ). This number of falls is rather small compared to previous reports. ${ }^{23,24}$ Yasumura et al reported that the annual rate of injurious fall in subjects older than 65 was $5.6 \%(74 / 1317)$ in a rural Japanese community. ${ }^{24}$ 
Table I Demographic characteristics

\begin{tabular}{|c|c|c|c|}
\hline & $\begin{array}{l}\text { Control } \\
(N=1 \mid 7)\end{array}$ & $\begin{array}{l}\text { POAG } \\
(N=101)\end{array}$ & $\boldsymbol{P}$-value* \\
\hline Age (years) & $60.2 \pm 7.5$ & $62.3 \pm 8.7$ & 0.06 \\
\hline Gender (male/female) & $77 / 40$ & $58 / 43$ & 0.21 \\
\hline BMI & $22.6 \pm 1.5$ & $22.5 \pm 3.0$ & 0.76 \\
\hline $\begin{array}{l}\text { Smoking history never } \\
\text { or former/current }\end{array}$ & $71 / 46$ & $77 / 24$ & 0.08 \\
\hline $\begin{array}{l}\text { Alcohol consumption } \\
\text { (daily/sometimes/none) }\end{array}$ & $29 / 40 / 48$ & $27 / 39 / 35$ & 0.64 \\
\hline $\begin{array}{l}\text { BCVA } \\
\text { (better eye; logMAR) }\end{array}$ & $0.01 \pm 0.05$ & $0.05 \pm 0.12$ & $<0.00 \mathrm{I}$ \\
\hline $\begin{array}{l}\text { BCVA } \\
\text { (worse eye; logMAR) }\end{array}$ & $0.03 \pm 0.08$ & $0.11 \pm 0.20$ & 0.001 \\
\hline $\begin{array}{l}\text { MD value } \\
\text { (better eye, } d B \text { ) }\end{array}$ & & $-3.8 \pm 4.1$ & \\
\hline $\begin{array}{l}\text { MD value } \\
\text { (worse eye, dB) }\end{array}$ & & $-7.3 \pm 5.2$ & \\
\hline Topical eye drop & & & \\
\hline Prostaglandin & & $90(90 / I 01=89.1 \%)$ & \\
\hline Beta blocker & & $58(58 / \mathrm{I} 0 \mathrm{I}=57.4 \%)$ & \\
\hline CAI & & $10(10 / 101=9.9 \%)$ & \\
\hline
\end{tabular}

Note: *Unpaired $t$-test or chi-square test was used depending on the variable (eg, continuous and categorical variables).

Abbreviations: POAG, primary open-angle glaucoma; BMI, body mass index; CAI, carbonic anhydrase inhibitor; BCVA, best corrected visual acuity; logMAR, logarithm of the minimum angle of resolution; MD, mean deviation.

The low injurious fall rate in our study may partially be explained by the following factors, which are all associated with the risk of falling ${ }^{11,25}$ : (1) the relative youth of the subjects enrolled in this study (ie, age is a significant risk factor for falls), (2) the exclusion of subjects with systemic disease, (3) the inclusion of fewer subjects with fall proneness (ie, multiple falls by the same individual may have been included in earlier reports), and (4) the male-skewed gender ratio in our study compared to previous studies (ie, being female is a significant risk factor for injurious falls).

The strengths of the present study are that (1) all of the subjects with POAG and the controls without POAG were examined by a single glaucoma specialist at a single institution, and (2) clear diagnostic criteria for POAG were applied.

The limitations are the following. (1) The long recall period might diminish the reporting accuracy. We sought to examine the association between relatively young glaucoma patients and falls, because the prevalence of glaucoma in Japan is 5\% in 40-year-old people. ${ }^{10}$ However, it is well known that young

Table 2 Number of injurious falls

\begin{tabular}{llll}
\hline Group & Control $(\mathbf{N}=\mathrm{II})$ & POAG $(\mathbf{N}=10 \mathrm{I})$ & P-value* \\
\hline Injurious fall & $\mathrm{I}(\mathrm{I} / \mathrm{II}=0.9 \%)$ & $7(7 / \mathrm{I0I}=6.9 \%)$ & 0.026 \\
\hline
\end{tabular}

Note: *Fisher's exact test.

Abbreviation: POAG, primary open-angle glaucoma.
Table 3 Demographic characteristics of non-fallers and fallers in subjects with primary open-angle glaucoma

\begin{tabular}{llll}
\hline & $\begin{array}{l}\text { Non-faller } \\
(\mathbf{N}=\mathbf{9 4})\end{array}$ & $\begin{array}{l}\text { Faller } \\
(\mathbf{N}=\mathbf{7})\end{array}$ & \begin{tabular}{l} 
P-value* \\
\hline Age
\end{tabular} \\
Gender (male/female) & $56 / 2 \pm 7.8$ & $77.0 \pm 6.6$ & $<0.00 \mathrm{I}$ \\
BMI & $22.8 \pm 2.9$ & $19.6 \pm 3.6$ & 0.006 \\
BCVA (better eye; logMAR) & $0.07 \pm 0.12$ & $0.54 \pm 0.45$ & $<0.00 \mathrm{I}$ \\
BCVA (worse eye; logMAR) & $0.04 \pm 0.08$ & $0.30 \pm 0.22$ & $<0.00 \mathrm{I}$ \\
MD in the better eye & $-3.2 \pm 3.5$ & $-10.7 \pm 5.8$ & $<0.00 \mathrm{I}$ \\
MD in the worse eye & $-6.6 \pm 4.5$ & $-15.8 \pm 7.1$ & $<0.00 \mathrm{I}$ \\
\hline
\end{tabular}

Note: *Unpaired $t$-test or Fisher exact test was used depending on the variable (eg, continuous and categorical variables).

Abbreviations: BMI, body mass index; BCVA, best corrected visual acuity; logMAR, logarithm of the minimum angle of resolution; MD, mean deviation.

subjects only rarely fall. Therefore, we used a long time frame to collect as many events as possible. Consequently, however, recall bias was an important limitation. (2) A relatively small number of participants reported injurious fall, especially among the control subjects in this study. (3) Recall inaccuracies and a reluctance to provide information might have affected the self-reported data. Subjects with POAG might remember an injurious fall better than subjects without POAG, which could increase the number of reported falls in POAG subjects. (4) Visual and ophthalmological data were obtained only after a fall had occurred, typically several years later. Therefore, the visual field of the subjects who fell may have differed at the time of the fall from that measured at the time of enrollment. Because we could not evaluate the patients' visual field when the fall occurred, the accuracy of our conclusion might be affected. (5) It is possible that in some cases the glaucoma severity was inaccurate because of the cross-sectional nature of the data and the progression of the disease over the long time frame. (6) We did not define the criteria for an injurious fall in this study. Thus, whether the outcome was a serious fall (one resulting in hospitalization or fracture), or one that caused a milder injury, such as soft tissue damage, bruises, or lacerations, was unknown. Therefore, the damage caused by the fall may have varied, and mild falls may not have been recorded. (7) We asked the patients to answer dichotomously, and did not collect the data as numbers of injurious falls. This was a limitation because the number of falls would have enabled more efficient analysis techniques, such as negative binomial regression models. (8) The exclusion of subjects with hypertension and diabetes mellitus was an important limitation. In the POAG group, these exclusion criteria meant that over $25 \%$ of the potential participants were excluded, and these would have likely been older patients. The relatively young age group 
examined would explain the small incidence of injurious falls in the cohort and significantly limits the generalizability of the study findings. (9) Recall inaccuracies and a reluctance to provide information may have affected the self-reported data. Cummings et al reported that up to $30 \%$ of falls are not recalled even in a 1 -year period; ${ }^{26}$ thus, there is likely to be significant recall bias in this study design.

The current study suggests that POAG is significantly associated with an increased risk for injurious fall.

\section{Disclosure}

The authors report no conflicts of interest in this work.

\section{References}

1. Ryynanen OP, Kivela SL, Honkanen R, Laippala P, Soini P. Incidence of falling injuries leading to medical treatment in the elderly. Public Health. 1991;105(5):373-386.

2. Tinetti ME, Speechley M, Ginter SF. Risk factors for falls among elderly persons living in the community. $N$ Engl J Med. 1988;319(26): 1701-1707.

3. Scheffer AC, Schuurmans MJ, van Dijk N, van der Hooft T, de Rooij SE. Fear of falling: measurement strategy, prevalence, risk factors and consequences among older persons. Age Ageing. 2008;37(1):19-24.

4. Kool B, Ameratunga S, Robinson E, Jackson R. Hospitalisations and deaths due to unintentional falls at home among working-aged New Zealanders. Injury. 2007;38(5):570-575.

5. Tinetti ME, Williams CS. Falls, injuries due to falls, and the risk of admission to a nursing home. N Engl J Med. 1997;337(18):1279-1284.

6. Kent A, Pearce A. Review of morbidity and mortality associated with falls from heights among patients presenting to a major trauma centre. Emerg Med Australas. 2006;18(1):23-30.

7. Driscoll TR, Mitchell RJ, Hendrie AL, Healey SH, Mandryk JA, Hull BP. Unintentional fatal injuries arising from unpaid work at home. Inj Prev. 2003;9(1):15-19.

8. Korhonen N, Niemi S, Parkkari J, Palvanen M, Kannus P. Unintentional injury deaths among adult Finns in 1971-2008. Injury. 2010;42(9): 885-888.

9. Foster A, Resnikoff S. The impact of Vision 2020 on global blindness. Eye. 2005;19(10):1133-1135.

10. Iwase A, SuzukiY, Araie M, et al. The prevalence of primary open-angle glaucoma in Japanese: the Tajimi Study. Ophthalmology. 2004;111(9): 1641-1648.
11. Nevitt MC, Cummings SR, Kidd S, Black D. Risk factors for recurrent nonsyncopal falls. A prospective study. JAMA. 1989;261(18): 2663-2668.

12. Klein BE, Klein R, Lee KE, Cruickshanks KJ. Performance-based and self-assessed measures of visual function as related to history of falls, hip fractures, and measured gait time. The Beaver Dam Eye Study. Ophthalmology. 1998;105(1):160-164.

13. Ivers RQ, Cumming RG, Mitchell P, Attebo K. Visual impairment and falls in older adults: the Blue Mountains Eye Study. J Am Geriatr Soc. 1998;46(1):58-64.

14. Coleman AL, Cummings SR, Yu F, et al. Binocular visual-field loss increases the risk of future falls in older white women. $J$ Am Geriatr Soc. 2007;55(3):357-364.

15. Lord SR, Dayhew J. Visual risk factors for falls in older people. $J \mathrm{Am}$ Geriatr Soc. 2001;49(5):508-515.

16. Lord SR, Menz HB. Visual contributions to postural stability in older adults. Gerontology. 2000;46(6):306-310.

17. Maino JH. Visual deficits and mobility. Evaluation and management Clin Geriatr Med. 1996;12(4):803-823.

18. Friedman DS, Freeman E, Munoz B, Jampel HD, West SK. Glaucoma and mobility performance: the Salisbury Eye Evaluation Project. Ophthalmology. 2007;114(12):2232-2237.

19. Glynn RJ, Seddon JM, Krug JH, Sahagian CR, Chiavelli ME, Campion EW. Falls in elderly patients with glaucoma. Arch Ophthalmol. 1991;109(2):205-210.

20. Haymes SA, Leblanc RP, Nicolela MT, Chiasson LA, Chauhan BC. Risk of falls and motor vehicle collisions in glaucoma. Invest Ophthalmol Vis Sci. 2007;48(3):1149-1155.

21. Guse CE, Porinsky R. Risk factors associated with hospitalization for unintentional falls: Wisconsin hospital discharge data for patients aged 65 and over. WMJ. 2003;102(4):37-42.

22. Lamoureux EL, Chong E, Wang JJ, et al. Visual impairment, causes of vision loss, and falls: the Singapore Malay eye study. Invest Ophthalmol Vis Sci. 2008;49(2):528-533.

23. Kannus P, Parkkari J, Koskinen S, et al. Fall-induced injuries and deaths among older adults. JAMA. 1999;281(20):1895-1899.

24. Yasumura S, Haga H, Niino N. Circumstances of injurious falls leading to medical care among elderly people living in a rural community. Arch Gerontol Geriatr. 1996;23(2):95-109.

25. Deandrea S, Lucenteforte E, Bravi F, Foschi R, La Vecchia C, Negri E. Risk factors for falls in community-dwelling older people: a systematic review and meta-analysis. Epidemiology. 2010;21(5):658-668.

26. Cummings SR, Nevitt MC, Kidd S. Forgetting falls. The limited accuracy of recall of falls in the elderly. J Am Geriatr Soc. 1988;36(7): 613-616.
Clinical Ophthalmology

\section{Publish your work in this journal}

Clinical Ophthalmology is an international, peer-reviewed journal covering all subspecialties within ophthalmology. Key topics include: Optometry; Visual science; Pharmacology and drug therapy in eye diseases; Basic Sciences; Primary and Secondary eye care; Patient Safety and Quality of Care Improvements. This journal is indexed on Submit your manuscript here: http://www.dovepress.com/clinical-ophthalmology-journal

\section{Dovepress}

PubMed Central and CAS, and is the official journal of The Society of Clinical Ophthalmology (SCO). The manuscript management system is completely online and includes a very quick and fair peer-review system, which is all easy to use. Visit http://www.dovepress.com/ testimonials.php to read real quotes from published authors. 